\title{
Alternatives to standard acute in-patient care in England: readmissions, service use and cost after discharge
}

Sarah Byford, Jessica Sharac, Brynmor Lloyd-Evans, Helen Gilburt, David P. J. Osborn, Morven Leese, Sonia Johnson and Mike Slade

\section{Background}

Residential alternatives to standard psychiatric admissions are associated with shorter lengths of stay, but little is known about the impact on readmissions.

\begin{abstract}
Aims
To explore readmissions, use of community mental health services and costs after discharge from alternative and standard services
\end{abstract}

\section{Method}

Data on use of hospital and community mental health services were collected from clinical records for participants in six alternative and six standard services for 12 months from the date of index admission.

\section{Results}

After discharge, the mean number and length of readmissions, use of community mental health services and costs did not differ significantly between standard and alternative services. Cost of index admission and total 12-month cost per participant were significantly higher for standard services.

\section{Conclusions}

Shorter lengths of stay in residential alternatives are not associated with greater frequency or length of readmissions or greater use of community mental health services after discharge.

\section{Declaration of interest}

None.
Cost-effectiveness analysis of residential alternatives to standard hospital-based mental health services for patients in crisis found alternatives to be associated with shorter lengths of stay and significantly lower costs but poorer staff-rated clinical outcomes than standard acute psychiatric wards. ${ }^{1}$ However, these findings refer only to the period between admission and discharge from the initial admitting service. It is important to determine whether shorter average lengths of stay in residential alternatives have an adverse impact on subsequent admissions or use of community mental health services after discharge. In addition, knowledge of patient and service variables significantly associated with subsequent use of services, and thus cost, would help to predict which people are likely to be intensive service users and to assess the appropriateness of this intensity. In the absence of resource constraints and systemic inefficiencies, the quantity of services received by people with mental health problems would be determined by need alone. In reality, however, a number of factors may influence resource use and thus the total cost of care. This paper explores medium-term use of hospital and community mental health services by participants admitted to six alternative and six standard services. The aims were to test first for differences in the number, length of stay and cost of admissions and the total cost of hospital and community mental health services over 12 months from date of index admission, and second for patient and service characteristics significantly associated with 12-month costs of care.

\section{Method}

Our observational cohort study involved 12 services, six providing a residential alternative to standard psychiatric in-patient services and six comparison standard acute wards accepting patients from similar catchment areas and where possible served by the same community mental health services. The characteristics of the six services are reported in detail elsewhere; ${ }^{2}$ they include a hospital unit implementing an innovative model intended to increase quantity and quality of contact between staff and patients, a short-stay ward intended to prevent longer-term admissions, community services integrated within crisis or community mental health teams, and non-clinical services managed by voluntary sector organisations. The study aimed to recruit 35-40 consecutively admitted patients at each site. Exclusion criteria were opting out of the study, being admitted for non-crisis purposes (e.g. planned respite care) and being transferred from another acute ward for non-clinical reasons. All participants received information through posters displayed on the unit and information sheets received at admission and at discharge, and were given the opportunity to opt out of the study.

\section{Measures}

Data on psychiatric admissions and use of all other hospital and community mental health services were collected from computerised patient activity records at each service, covering the 12-month period from date of index admission to the service. All unit costs were calculated for the financial year 2006-7. The manager of each alternative service provided budget data for the service to calculate cost per bed-day. National average unit costs were applied to standard admissions and all other mental health services. ${ }^{3,4}$ Outcome measures assessed at baseline in the original observational study and used in the current analyses included the Health of the Nation Outcome Scales (HoNOS) measure of social disability ${ }^{5}$ the Global Assessment of Functioning (GAF) measure of symptoms and social functioning, ${ }^{6}$ and the Threshold Assessment Grid (TAG) measure of severity of mental health problems across the domains of need, safety and risk. ${ }^{7}$

\section{Statistical analysis}

Service use data are reported descriptively. Despite skewed cost distributions, differences in the cost of standard and alternative 
services were tested using standard parametric tests and the validity and robustness of the results confirmed using nonparametric bootstrap techniques, ${ }^{8}$ as recommended by Thompson \& Barber. ${ }^{9}$ Analyses were adjusted for area (six areas associated with the six paired comparison sites) and for possible confounding factors identified as predictors of being admitted to an alternative rather than a standard service. ${ }^{2}$ These included age, gender, ethnic group (White, Black or 'other'), born in the UK (yes/no), patient initiated help-seeking (yes/no), previously known to services (yes/no), baseline behaviour problems as determined by the HoNOS (behaviour subscale score $\geqslant 5$ ), baseline risk of harm to others as determined by the TAG (item 4 score $\geqslant$ moderate risk), baseline GAF symptoms score and the cost of psychiatric admissions in the 12 months prior to study entry. Single imputation using multiple regression was used for missing items (approximately $6 \%$ of the data). Results from complete case analyses did not differ significantly and so are not reported here.

Univariate associations between baseline characteristics and total costs over the 12-month follow-up period were investigated. Results for continuous variables are presented in two groups split at the median value, but analyses were carried out on the continuous data. Multiple regression was used to reduce the variable list to those independently associated with follow-up costs, using a process outlined in previous research. ${ }^{10}$ This involved, in the first instance, fitting a multiple regression model which included all variables that had important univariate associations with costs and then discarding from this model all variables that ceased to be important. Second, each variable that did not have a univariate association with costs was added, one at a time, and retained if it added significantly to the model or otherwise discarded. The model finally arrived at was checked to ensure that none of the terms currently excluded would add significantly to it. In carrying out this procedure a significance level of $10 \%$ was used.

\section{Results}

A total of 433 participants entered the study (between 34 and 40 per service). Detailed baseline characteristics are presented elsewhere, ${ }^{1,2}$ and on the whole the alternative services were seen as accepting a clinical population overlapping with but not identical to hospital services. One alternative service was found to closely resemble standard in-patient services in terms of patient profile, content of care, length of stay and outcomes, ${ }^{2,11}$ and thus was excluded from the current analyses, reducing the number of participants to 398. Basic demographic details are presented in Table 1. Data on use of mental health services were available for all 398 participants from six standard services $(n=222)$ and five alternative services $(n=176)$.

\section{Mental health service use and cost}

Contacts with mental health services in the 12 months before and after the date of index admission are reported in Table 2. In the year before index admission those admitted to standard services spent 22 days on average in hospital for psychiatric reasons, compared with 27 days for those admitted to an alternative service (mean difference 5 days). In the 12 months following the date of index admission the mean number of psychiatric in-patient days was much greater (standard service 70 days, alternative service 57 days; mean difference 13 days). Observed differences between groups were evident for the mean duration of the index admission (standard service 44 days, alternative service 29 days; mean difference 15 days) but not for subsequent admissions (standard service 26 days, alternative service 28 days;

\begin{tabular}{|c|c|c|}
\hline & $\begin{array}{l}\text { Standard } \\
\text { service } \\
(n=222)\end{array}$ & $\begin{array}{l}\text { Alternative } \\
\text { service } \\
(n=176)\end{array}$ \\
\hline Male gender, $n(\%)$ & $120(54)$ & $86(49)$ \\
\hline Age, years: mean (s.d.) ${ }^{a}$ & 39 (13) & $42(13)$ \\
\hline $\begin{array}{l}\text { Marital status, } n(\%)^{\text {a }} \\
\text { Unmarried } \\
\text { Married/cohabiting } \\
\text { Separated/divorced/widowed }\end{array}$ & $\begin{array}{r}113(54) \\
64(30) \\
33(16)\end{array}$ & $\begin{array}{r}101(61) \\
27(16) \\
38(23)\end{array}$ \\
\hline $\begin{array}{l}\text { Ethnicity, } n(\%) \\
\text { White British } \\
\text { Black Caribbean } \\
\text { Black African }\end{array}$ & $\begin{array}{c}159(72) \\
8(4) \\
8(4)\end{array}$ & $\begin{array}{c}120(68) \\
23(13) \\
12(7)\end{array}$ \\
\hline Born in UK, $n(\%)^{a}$ & $170(81)$ & $149(85)$ \\
\hline $\begin{array}{l}\text { Time since first contact with mental } \\
\text { health services, } n(\%)^{a} \\
\text { Less than } 2 \text { years } \\
2-5 \text { years } \\
\text { More than } 5 \text { years }\end{array}$ & $\begin{array}{l}86(42) \\
37(18) \\
83(40)\end{array}$ & $\begin{array}{l}52(31) \\
30(18) \\
84(51)\end{array}$ \\
\hline $\begin{array}{l}\text { Contact with mental health services } \\
\text { in } 3 \text { months preceding admission, } n \text { (\%) }\end{array}$ & $128(58)$ & $125(71)$ \\
\hline Patient initiated help-seeking, $n(\%)^{a}$ & $36(17)$ & $53(31)$ \\
\hline
\end{tabular}

mean difference 2 days). Participants admitted to alternative services had slightly more contact with community mental health teams, early intervention services and crisis teams, whereas participants admitted to standard services were seen to have more contact with assertive outreach teams.

Total costs per participant are reported in Table 3. There was no significant difference in mean costs between standard and alternative services for psychiatric admissions in the 12 months prior to index admission (mean UKE5685 standard, $\mathfrak{E} 6560$ alternative; mean difference $\mathfrak{E} 875, P=0.5$ ) or total use of mental health services subsequent to the index admission (mean $\mathfrak{E} 8228$

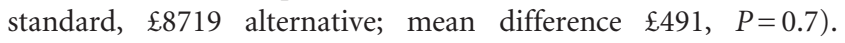
However, large differences in the mean costs of the index

Table 2 Mental health service use before and after index admission

$\begin{array}{ccc} & \text { Standard } & \text { Alternative } \\ \text { service } & \text { service } \\ (n=222) & (n=176) \\ \text { Mean (s.d.) } & \text { Mean (s.d.) }\end{array}$

\begin{tabular}{|lcc|}
\hline $\begin{array}{l}\text { Year preceding date of index admission } \\
\text { Psychiatric in-patient stay, days }\end{array}$ & $22(50)$ & $27(56)$ \\
\hline $\begin{array}{l}\text { Year following date of index admission } \\
\text { Number of psychiatric admissions }\end{array}$ & & \\
including index admission & $2(1)$ & $2(1)$ \\
Index admission days & & \\
Post-index admission psychiatric & $44(58)$ & \\
in-patient days & & \\
Total psychiatric in-patient days & $26(52)$ & $28(58)$ \\
Psychiatric out-patient attendances & $70(77)$ & $57(79)$ \\
Psychiatric day hospital attendances & $3(4)$ & $2(2)$ \\
CMHT contacts & $3(10)$ & $5(16)$ \\
Assertive outreach team contacts & $9(16)$ & $14(19)$ \\
Early intervention service contacts & $5(23)$ & $3(11)$ \\
Community rehabilitation team contacts & $0(1)$ & $2(15)$ \\
Crisis resolution team contacts & $7(5)$ & $1(5)$ \\
A\&E/liaison psychiatry contacts & $0(1)$ & $9(17)$ \\
\end{tabular}

A\&E, accident and emergency; $C M H T$, community mental health team. a. Index admissions include transfers from the initial admitting service to other facilities, not previously reported by Slade et al. 


\begin{tabular}{|c|c|c|c|c|c|}
\hline & \multicolumn{3}{|c|}{ Cost per participant, UKf } & \multirow[b]{2}{*}{$P$} & \multirow[b]{2}{*}{ Adjusted $P^{c}$} \\
\hline & $\begin{array}{c}\text { Standard service } \\
(n=222) \text { Mean (s.d.) }\end{array}$ & $\begin{array}{l}\text { Alternative service } \\
(n=176) \text { Mean (s.d.) }\end{array}$ & $\begin{array}{l}\text { Mean difference } \\
\qquad(95 \% \mathrm{Cl})\end{array}$ & & \\
\hline \multicolumn{6}{|l|}{ Year preceding study entry } \\
\hline Psychiatric admissions & $5685(12868)$ & $6560(13687)$ & $-875(-3502$ to 1751$)$ & 0.513 & \\
\hline \multicolumn{6}{|l|}{ Year following study entry } \\
\hline Index admission & $11060(15033)$ & $6233(13267)$ & 4827 (2034 to 7620$)$ & 0.001 & 0.005 \\
\hline Subsequent psychiatric admissions & $6525(13311)$ & 6477 (13041) & 47 (-2570 to 2665$)$ & 0.972 & 0.878 \\
\hline Psychiatric out-patient attendances & $382(494)$ & $283(298)$ & $100(21$ to 178$)$ & 0.013 & 0.002 \\
\hline Psychiatric day hospital attendances & 237 (965) & $471(1522)$ & $-234(-493$ to 25$)$ & 0.077 & 0.054 \\
\hline CMHT contacts & $638(1148)$ & 1006 (1349) & $-368(-619$ to -117$)$ & 0.004 & 0.017 \\
\hline Assertive outreach team contacts & $185(924)$ & $100(446)$ & 85 (-64 to 234) & 0.264 & 0.179 \\
\hline Early intervention service contacts & $3(22)$ & 65 (424) & $-62(-125$ to 1$)$ & 0.053 & 0.027 \\
\hline Community rehabilitation team contacts & 44 (339) & $57(372)$ & $-12(-83$ to 58$)$ & 0.728 & 0.910 \\
\hline Crisis resolution team contacts & $186(354)$ & $234(442)$ & $-49(-127$ to 30$)$ & 0.224 & 0.238 \\
\hline A\&E/liaison psychiatry contacts & $28(111)$ & $26(68)$ & $2(-16$ to 21$)$ & 0.815 & 0.949 \\
\hline Total cost subsequent to index admission & $8228(13590)$ & 8719 (13603) & $-491(-3189$ to 2206$)$ & 0.721 & 0.847 \\
\hline Total 12-month cost including index admission & $19288(20044)$ & $14952(19026)$ & 4336 (447 to 8225) & 0.029 & 0.049 \\
\hline
\end{tabular}

admission were evident ( $£ 11060$ standard, $£ 6233$ alternative) resulting in statistically significant differences in total cost per participant over the full 12-month follow-up period (mean

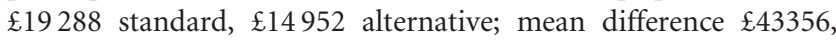
$P=0.03$ ). Adjusted analyses did not alter the significance of these findings. Across all services participants cost just over $\mathfrak{E} 17000$ per annum on average, with psychiatric in-patient admissions accounting for $89 \%$.

Index admissions, including length of stay in the initial admitting service and subsequent moves as part of the index admission, were found to vary considerably in terms of mean length of stay (range 25-64 days standard, 16-61 days alternative)

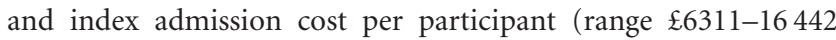
standard, £3293-12336 alternative) (Table 4). Non-clinical and crisis team bed alternatives were found to have the shortest index admission duration on average (mean 17 days), whereas the clinical crisis house had the second longest index admission of all services (mean 61 days). Despite having the shortest duration of stay in the initial admitting service (mean 1.2 days), the short-stay psychiatric ward fell in between these two extremes (mean 35 days index admission) as a result of having the longest stays in subsequent index admission services. This contrasts with a mean index admission duration of 44 days in the standard services. The pattern for costs was the same, with the non-clinical and crisis team bed alternatives being associated with the lowest index admission and total 12-month costs of all services, the clinical crisis house being the most expensive in terms of total 12-month costs and the third most expensive in terms of index admission costs, and the short-stay ward being located between the two.

\section{Factors associated with costs}

Univariate associations with total 12-month costs are reported in Table 5. In addition to allocation to standard $v$. alternative services, higher total costs per participant were significantly associated with older age, being previously known to services, help-seeking not initiated by the patient, risk of harm to others and higher cost of psychiatric admissions in the 12 months prior to index admission.

Table 6 details the final multiple regression model, which found the same associations to be significant as in the univariate

\begin{tabular}{|c|c|c|c|c|c|c|c|c|c|c|}
\hline \multirow[b]{2}{*}{$\begin{array}{l}\text { Type } \\
\text { of service }\end{array}$} & \multirow[b]{2}{*}{$\begin{array}{l}\text { Description of } \\
\text { alternative service }\end{array}$} & \multicolumn{4}{|c|}{ Length of stay, days (mean) } & \multicolumn{5}{|c|}{ Cost, UKf (mean) } \\
\hline & & $\begin{array}{c}\text { First } \\
\text { service }\end{array}$ & $\begin{array}{l}\text { Second } \\
\text { service }\end{array}$ & $\begin{array}{c}\text { Third } \\
\text { service }\end{array}$ & $\begin{array}{l}\text { Total length } \\
\text { of index } \\
\text { admission }^{\text {b }}\end{array}$ & $\begin{array}{c}\text { First } \\
\text { service }\end{array}$ & $\begin{array}{l}\text { Second } \\
\text { service }\end{array}$ & $\begin{array}{c}\text { Third } \\
\text { service }\end{array}$ & $\begin{array}{l}\text { Total cost } \\
\text { of index } \\
\text { admission }\end{array}$ & $\begin{array}{l}\text { Total } \\
\text { 12-month } \\
\text { costs }\end{array}$ \\
\hline Alternative & Crisis team beds & 7.1 & 8.3 & 0.3 & 15.7 & 1386 & 2130 & 67 & 3583 & 10669 \\
\hline Alternative & Non-clinical 1 & 16.4 & 0.5 & 0.0 & 16.9 & 3187 & 105 & 0 & 3293 & 8660 \\
\hline Alternative & Non-clinical 2 & 15.6 & 1.6 & 0.0 & 17.2 & 3032 & 405 & 0 & 3437 & 11244 \\
\hline Standard & & 23.5 & 1.3 & 0.0 & 24.8 & 6060 & 251 & 0 & 6311 & 14067 \\
\hline Standard & & 32.5 & 0.1 & 0.0 & 32.7 & 8395 & 33 & 0 & 8428 & 15080 \\
\hline Alternative & Short-stay ward & 1.2 & 33.4 & 0.0 & 34.6 & 238 & 8604 & 0 & 8842 & 18859 \\
\hline Standard & & 43.1 & 0.6 & 0.0 & 43.7 & 11116 & 122 & 0 & 11238 & 19232 \\
\hline Standard & & 44.3 & 1.4 & 0.0 & 45.7 & 11431 & 159 & 0 & 11591 & 23602 \\
\hline Standard & & 36.4 & 8.6 & 5.5 & 50.4 & 9379 & 1979 & 1409 & 12766 & 21064 \\
\hline Alternative & Clinical crisis house & 53.9 & 7.3 & 0.0 & 61.2 & 10464 & 1873 & 0 & 12336 & 26040 \\
\hline Standard & & 50.4 & 13.3 & 0.0 & 63.7 & 13011 & 3432 & 0 & 16442 & 22870 \\
\hline
\end{tabular}


analyses. Total 12-month follow-up costs were found to increase

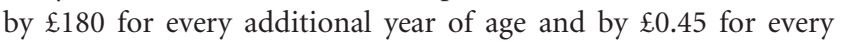

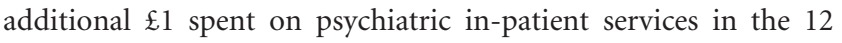
months before entry to the study. Participants known to services cost almost $\mathfrak{E} 7000$ more than participants not known to services, on average. Participants assessed by the TAG as at risk of harm to others cost almost $\mathfrak{E} 5500$ more than participants not at risk of harm to others. Participants who initiated help-seeking were found to cost $£ 4000$ less on average than participants who did not initiate help-seeking, although this relationship was weak. The model was able to explain around $20 \%$ of the variation in total follow-up costs (adjusted $R^{2}=0.19$ ).

\section{Discussion}

Index admissions to alternative services were on average shorter and thus cheaper than index admissions to standard services.

Table 5 Univariate associations with total 12-month costs

\begin{tabular}{|c|c|c|c|}
\hline & \multicolumn{3}{|c|}{ Cost per participant, $f$} \\
\hline \multicolumn{4}{|l|}{ Service } \\
\hline Standard & 222 & $19288(20044)$ & \\
\hline Alternative & 176 & $14952(19026)$ & 0.029 \\
\hline \multicolumn{4}{|l|}{$\mathrm{Age}^{\mathrm{a}}$} \\
\hline$\leqslant 40$ years & 206 & 16532 (19382) & \\
\hline$>40$ years & 187 & $18362(20181)$ & 0.030 \\
\hline \multicolumn{4}{|l|}{ Gender } \\
\hline Male & 206 & $17688(20044)$ & \\
\hline Female & 192 & $17031(19358)$ & 0.740 \\
\hline \multicolumn{4}{|l|}{ Ethnicity } \\
\hline White & 310 & $17969(20170)$ & \\
\hline Black & 53 & $16258(18257)$ & \\
\hline Other & 35 & 13757 (17 408) & 0.443 \\
\hline \multicolumn{4}{|l|}{ Born in the UK } \\
\hline Yes & 319 & $17613(20067)$ & \\
\hline No & 64 & $16581(18493)$ & 0.704 \\
\hline \multicolumn{4}{|c|}{ Known to services } \\
\hline Yes & 253 & $20208(21040)$ & \\
\hline No & 145 & 12421 (15994) & $<0.001$ \\
\hline \multicolumn{4}{|l|}{ Self-referral } \\
\hline Yes & 89 & 11924 (15944) & \\
\hline No & 293 & $18698(20138)$ & 0.004 \\
\hline \multicolumn{4}{|c|}{ GAF symptom score ${ }^{a}$} \\
\hline$\leqslant 52$ & 202 & $18648(21104)$ & \\
\hline$>52$ & 193 & 16199 (18189) & 0.238 \\
\hline \multicolumn{4}{|c|}{ TAG risk of harm to others } \\
\hline Yes & 93 & $22181(23627)$ & \\
\hline No & 305 & $15904(18120)$ & 0.007 \\
\hline \multicolumn{4}{|c|}{ HoNOS behaviour problems } \\
\hline Yes & 98 & $18657(23360)$ & \\
\hline No & 300 & $16951(18364)$ & 0.457 \\
\hline \multicolumn{4}{|c|}{$\begin{array}{l}\text { Cost of admissions } \\
\text { in previous year }{ }^{\text {a }}\end{array}$} \\
\hline 0 & 220 & $14189(16461)$ & \\
\hline$>0$ & 178 & $21303(22507)$ & $<0.0001$ \\
\hline \multicolumn{4}{|l|}{ Area } \\
\hline 1 & 70 & $15238(17268)$ & \\
\hline 2 & 68 & $23332(20775)$ & \\
\hline 3 & 70 & 16769 (22149) & \\
\hline 4 & 39 & $15080(12281)$ & \\
\hline 5 & 77 & $16556(21672)$ & \\
\hline 6 & 74 & 16535 (18924) & 0.470 \\
\hline \multicolumn{4}{|c|}{$\begin{array}{l}\text { GAF, Global Assessment of Functioning; HoNOS, Health of the Nation Outcome Scales; } \\
\text { TAG, Threshold Assessment Grid. } \\
\text { a. Summarised as two groups split at the median, but } P \text { values relate to analysis on } \\
\text { a continuous scale. }\end{array}$} \\
\hline
\end{tabular}

The use and cost of subsequent admissions and other hospital and community mental health services differed little between the two groups, resulting in significantly lower 12-month total costs for patients in the alternative services. These findings suggest that shorter lengths of stay in alternative services are not associated with a greater need for subsequent admissions or for support from other hospital or community mental health services. There was some evidence to suggest that participants admitted to alternative services made more use of community-based services, in particular community mental health teams, early intervention services and crisis teams, but these differences were not large or significant and may be due to the longer length of time spent in the community over the 12 -month period of follow-up.

The overall service use and cost results mask substantial variation between the services, with non-clinical alternatives and crisis team beds being associated with the shortest lengths of stay and lowest costs, whereas the clinical crisis house was found to be one of the most expensive services. This suggests a trend for clinical services, irrespective of type, to involve longer duration of stay and greater costs than non-clinical services, with even the short-stay psychiatric ward involving much greater lengths of stay and costs than the cheaper non-clinical alternative services. However, there is also evidence to suggest that participants admitted to clinical alternatives differed very little from patients in the comparison standard service, in contrast to participants admitted to non-clinical alternatives who were significantly more likely to be known to services, to be self-referred and to cooperate with assessment, and were significantly less likely to have psychotic symptoms, to be admitted through accident and emergency departments or the police and criminal justice system, to have behaviour problems and to be perceived as posing a risk of harm to others. ${ }^{2}$ Thus the shorter lengths of stay and lower costs observed in the non-clinical alternatives may be explained to a large extent by the fact that they appear to be admitting a less severely affected group of patients.

There is little existing evidence with which to compare these results. A pilot patient-preference evaluation of women's crisis houses compared with standard psychiatric admission found similar results in terms of service use, ${ }^{12}$ reporting mean index admission lengths of 33 days per participant compared with 37 in the study reported here. More detailed comparisons of service use and cost beyond the index admission were not possible because of the different periods over which the two studies collected service use data. However, Howard et al over a 3-month period found psychiatric in-patient admissions accounted for $85 \%$ of total costs, compared with $89 \%$ in our study, again supporting the conclusion that they recruited a similar population. ${ }^{12}$

\section{Factors associated with high cost}

Analysis of factors associated with follow-up costs suggest that patients not initiating help-seeking, those at risk of harm to others, those with admissions in the recent past and those who

\begin{tabular}{|c|c|c|}
\hline & $\begin{array}{c}\text { Coefficient } \\
(95 \% \mathrm{Cl})\end{array}$ & $P$ \\
\hline Service - standard $v$. alternative & 4147 (400 to 7893) & 0.030 \\
\hline Age & 180 (42 to 318$)$ & 0.011 \\
\hline Known to services - yes $v$. no & 6844 (3011 to 10677) & 0.001 \\
\hline Patient initiated help-seeking - yes $v$. no & $-3914(-8211$ to 383$)$ & 0.074 \\
\hline Risk of harm to others - yes $v$. no & 5456 (1148 to 9764) & 0.013 \\
\hline Pre-index cost of psychiatric admissions & $0.45(0.31$ to 0.58$)$ & 0.000 \\
\hline
\end{tabular}


are older are likely to be high-cost service users and to require relatively long admissions on average. Being at risk of harm to others and not initiating help-seeking were found to be significantly associated with admission to a standard service, ${ }^{2}$ which is in turn associated with longer lengths of stay and thus higher costs. In contrast, being previously known to services was found to be significantly associated with admission to an alternative service, ${ }^{2}$ which in turn is associated with lower costs on average. In the current analysis, however, this group was in fact found to be more expensive than those not previously known to services. Exploration of the data suggests this is due to longer duration of index admission on average (mean 32 days for those known to services, 18 days for those not known to services).

\section{Limitations}

This study was limited by the use of an observational design. Participants were not randomly allocated between the two service types, and differences between the two groups at baseline were evident on a number of measures, with participants in standard services being more likely to experience psychotic symptoms, to be perceived as a risk to others, to be compulsorily detained and to be admitted through the accident and emergency department or the police and criminal justice system, and less likely to have referred themselves for help in the current crisis. ${ }^{2}$ However, there were substantial similarities between the two groups, and adjustment for baseline differences, including symptoms, risk of harm to others, behaviour problems and self-referral, did not have an impact on the results reported.

An important limitation of the analyses presented was the lack of an assessment of patient outcomes at the 12-month follow-up point, which meant that a full economic evaluation was not possible. In a separate paper we present short-term evidence of the relative cost-effectiveness of admission to alternatives compared with standard services, which used data on costs and outcomes covering the period between admission and discharge from the initial admitting service. ${ }^{1}$ The results suggest a tradeoff between the two service types, with standard services demonstrating better staff-rated clinical outcomes, but for greater cost as a result of longer periods of stay. However, it is possible that greater improvement in outcome for the standard services was partly or wholly due for some patients to the longer duration of stay associated with admission to a standard service, so these short-term findings are inconclusive, and a key question raised by these results is what happens to costs and outcomes following discharge. Although patient interviews after discharge from the initial admitting service were not feasible within the scope of this study, using readmissions as a proxy for outcome over the medium term suggests that although the cost advantage of the alternative services remains, the outcome advantage for standard services is diminished.

Reliance on psychiatric admission and other hospital and community mental health service data available from patient activity systems resulted in a cost perspective that was necessarily narrow, excluding hospital services for reasons other than mental health, primary healthcare services, social services, criminal justice system costs and productivity losses as a result of time off work due to illness. However, previous research suggests that hospital and community mental health services contribute the greatest proportion of the total costs of caring for people with severe mental health problems, ${ }^{13,14}$ so a broader perspective is unlikely to have a substantial impact on the reported results.

The generalisability of the results is also uncertain. Although the alternative services included in the analysis were selected to be representative of the main types of alternatives identified in
England, ${ }^{15}$ clear differences between alternative service types were evident, in particular between clinical and non-clinical alternatives, making interpretation of the overall findings difficult. Although clinical alternatives tended to be similar to standard services in terms of patient characteristics, service use and costs, non-clinical services appear to admit a somewhat different group of patients and were found to be associated with much shorter lengths of stay and total costs than standard services or clinical alternatives.

The absence of a clear-cut cost-effectiveness advantage for either type of service suggests that commissioners may need to take other factors into account when considering the development of services for this population. Such factors include the experience and satisfaction of service users, with both quantitative and qualitative evidence to support an overall preference for residential alternatives as a result of greater levels of freedom, safety and autonomy and lower levels of coercion and negative experiences, ${ }^{16,17}$ and evidence of improvements in outcome for patients in both standard and alternative services. ${ }^{1}$ These factors must be considered alongside concerns regarding the risk of harm to others and the need for compulsory admission, both of which may be criteria for exclusion from alternative services.

\section{Sarah Byford, PhD, Jessica Sharac, MPH, Health Service and Population Research Department, Institute of Psychiatry, King's College London; Brynmor Lloyd-Evans $\mathrm{PhD}$, Department of Mental Health Sciences, University College London; Helen Gilburt, PhD, Health Service and Population Research Department, Institute of Psychiatry, King's College London; David P. J. Osborn, PhD, Department of Mental Health Sciences, University College London; Morven Leese, PhD, Health Service and Population Research Department, Institute of Psychiatry, King's College London; Sonia Johnson, DM, Department of Mental Health Sciences, University College London; Mike Slade, PhD, Health Service and Population Research Department, Institute of Psychiatry, King's College London, London, UK \\ Correspondence: Dr Sarah Byford, Centre for the Economics of Mental Health, Box P024, Institute of Psychiatry, De Crespigny Park, London SE5 8AF, UK. Email:} s.byford@iop.kcl.ac.uk

\section{Funding}

This project was funded by the National Institute for Health Research Service Delivery and Organisation programme (project number 08/1304/075).

\section{Acknowledgements}

This study was undertaken in the context of the NIHR Specialist Mental Health Biomedical Research Centre at the Institute of Psychiatry, King's College London and the South London and Maudsley NHS Foundation Trust. The study was supported by the Mental Health and Maudsley NHS Foundation Trust. The study was supported by the Mental Health
Research Network (MHRN) and associated with the MHRN acute care group (convenor S.J.). The views expressed in this paper are those of the authors and not necessarily those of the NHS, the NIHR or the Department of Health.

\section{References}

1 Slade M, Byford S, Barrett B, Lloyd-Evans B, Gilburt H, Osborn DPJ, et al. Alternatives to standard acute in-patient care in England: short-term clinical outcomes and cost-effectiveness. Br J Psychiatry 2010 (suppl 53): s14-9.

2 Johnson S, Lloyd-Evans B, Morant N, Gilburt H, Shepherd G, Slade M, et al. Alternatives to standard acute in-patient care in England: roles and populations served. Br J Psychiatry 2010 (suppl 53): s6-13.

3 Curtis L. The Unit Costs of Health and Social Care 2007. Personal Social Services Research Unit, 2007

4 Department of Health. NHS Reference Costs 2007. Department of Health, 2007.

5 Wing JK, Beevor AS, Curtis RH, Park SB, Hadden S, Burns A. Health of the Nation Outcome Scales (HoNOS). Research and development. Br J Psychiatry 1998; 172: 11-8.

6 Jones SH, Thornicroft G, Coffey M, Dunn G. A brief mental health outcome scale - reliability and validity of the Global Assessment of Functioning (GAF). Br J Psychiatry 1995; 166: 654-9.

7 Salvi G, Leese $M$, Slade $M$. Routine use of mental health outcome assessments: choosing the measure. Br J Psychiatry 2005; 186: 146-52. 
8 Efron B, Tibshirani RJ. An Introduction to the Bootstrap. Chapman \& Hall, 1993.

9 Thompson SG, Barber JA. How should cost data in pragmatic randomised trials be analysed? BMJ 2000; 320: 1197-200.

10 Byford S, Barber JA, Harrington R. Factors that influence the cost of deliberate self-poisoning in children and adolescents. J Ment Health Policy Econ 2001; 4: 113-21.

11 Lloyd-Evans B, Johnson S, Morant N, Gilburt H, Osborn DPJ, Jagielska D, et al. Alternatives to standard acute in-patient care in England: differences in content of care and staff-patient contact. Br J Psychiatry 2010 (suppl 53): s46-51.

12 Howard L, Flach C, Leese M, Byford S, Killaspy H, Cole L, et al. Effectiveness and cost-effectiveness of admissions to women's crisis houses compared with traditional psychiatric wards: pilot patient-preference randomised controlled trial. Br J Psychiatry 2010 (suppl 53): s32-40.

13 Byford S, Fiander M, Torgerson DJ, Barber JA, Thompson SG, Burns T, et al. Cost-effectiveness of intensive $v$. standard case management for severe psychotic illness: UK700 case management trial. Br J Psychiatry 2009; 176 $537-43$.

14 Mccrone P, Johnson S, Nolan F, Pilling S, Sandor A, Hoult J, et al. Economic evaluation of a crisis resolution service: a randomised controlled trial. Epidemiol Psichiatr Soc 2009; 18: 54-8.

15 Johnson S, Gilburt H, Lloyd-Evans B, Osborn DPJ, Boardman J, Leese M, et al. In-patient and residential alternatives to standard acute psychiatric wards in England. Br J Psychiatry 2009; 194: 456-63.

16 Gilburt H, Slade M, Rose D, Lloyd-Evans B, Johnson S, Osborn DPJ. Service users' experience of residential alternatives to standard acute wards: qualitative study of similarities and differences. Br J Psychiatry 2010 (suppl 53): s26-31.

17 Osborn DPJ, Lloyd-Evans B, Johnson S, Gilburt H, Byford S, Leese M, et al. Residential alternatives to acute in-patient care in England: satisfaction, ward atmosphere and service user experiences. Br J Psychiatry 2010 (suppl 53): s41-6. 